\title{
Workshop 3 report: Sustainable funding sources and related cost benefit measurements
}

\author{
John Stanley ${ }^{\text {a, }}$, David Levinson ${ }^{\mathrm{b}}$ \\ a Institute of Transport and Logistics Studies, University of Sydney Business School, The University of Sydney, NSW 2006, Australia \\ ${ }^{\mathrm{b}}$ Department of Civil, Environmental, and Geo- Engineering, University of Minnesota, MN, USA
}

\section{A R T I C L E I N F O}

Article history:

Received 13 October 2016

Accepted 13 October 2016

Available online $\mathrm{xxx}$

\section{Jel codes:}

H7

I31

R14

R41

R48

R58

Keywords:

Benefit measurement

Externalities

Fares

Marginal social cost pricing

Public private partnership

Value capture

\begin{abstract}
A B S T R A C T
Recognising that public transport services generally deliver substantial benefits for society but frequently require operating and capital funding support, this Workshop sought to find ways to bridge this benefit/ funding gap, particularly through benefit monetization. It elaborated a wide range of benefits from public transport services, to both users and non-users. In regard to non-users, there was a particular focus on the role of public transport in promoting positive external benefits, such as agglomeration economies, and reducing the negative external costs of car use. A number of ways in which the service funding requirement might be reduced by improved system management were considered, such as better fare evasion practices and more effective public private partnerships. A range of funding opportunities was then reviewed, from which two preferred bundles were developed. Value capture was seen as a vital funding opportunity, both for supporting operating funding and capital funding requirements. Funding circumstances that were seen as more properly a governmental responsibility were identified.
\end{abstract}

(c) 2016 Elsevier Ltd. All rights reserved.

\section{Context}

Recent Thredbo Conferences have broadened their public transport discussion agenda beyond ownership, contracting and privatisation into wider contemporary public transport policy issues. Workshop 3 at Thredbo 14 continued that trend, partly building on discussions from Workshop 6 at Thredbo 13 on 'Delivering Sustainable Public Transport' (Stanley \& Lucas, 2014). That workshop underlined the importance of sustainable funding streams for sustainable public transport, emphasising that sustainable funding depends, in turn, on a clear understanding of the fundamental public transport value creation proposition, but that Workshop did not explore the value creation-funding link in any detail. Workshop 3 at Thredbo 14 built on this foundation by seeking to comprehensively identify the benefits and costs of public

\footnotetext{
* Corresponding author.

E-mail addresses: John.Stanley@sydney.edu.au (J. Stanley), dlevinson@umn.edu (D. Levinson).
}

transport and then link this to possible means of funding services and service improvements. Such funding will ultimately come from either government, at some level, users or others who benefit in some way from public transport services. A fundamental underlying proposition for Workshop 3 participants was that if public transport delivers significant community benefits, as participants accepted, then improved identification, measurement and monetization of those benefits should be of considerable assistance for sourcing the scarce funding needed for system and service operation and improvement. Public transport benefit analysis thus provides a foundation for a sustainable funding proposition.

The Workshop had 22 participants from eight countries (Australia, Brazil, Chile, Mexico, Norway, South Africa, Sweden and the US), coming from government, academic, NGO and industry backgrounds. Fourteen papers informed Workshop discussion, covering theory, policy analysis, case studies and/or evaluation. Workshop discussions were structured around groups of papers on fare policy and fare evasion (discussed in section 2), scoping and valuing public transport benefits and costs (Section 3), some aspects of service delivery to ensure efficient outcomes and hence 
reduce funding requirements, including some aspects of Public Private Partnerships (Section 4), and on funding mechanisms (section 5). The current paper is organized around these themes. In subject areas where the workshop lacked papers, comprehensive discussion provided the basis for Workshop findings. The Workshop concluded by forming proposals for policy, research and for future Thredbo Conference agendas (Section 6).

\section{Fare policy and fare evasion}

A fundamental welfare economic proposition underlying efficient resource allocation is that users of some particular service should meet the marginal social costs attributable to their use of that service, including net external costs imposed on others, unless there are particular identifiable policy reasons for doing otherwise. Exceptions usually involve concerns about the adverse distributional consequences (regressive outcomes) from applying this marginal social cost pricing rule.

In public transport terms, user pays is largely about fare setting. The Workshop paper by Pillay and Ngcobo (2015) discussed a number of the key policy issues involved in fare setting, using South African examples. They argue that a desirable transport subsidy framework for South Africa (part of which reflects the costs of fare concessions) must: (1) address social equity associated with structural poverty (where they observe that many low income households spend more than $20 \%$ of their household budget on public transport, including minibuses); (2) encourage the productivity of public transport operations (where they outline how offpeak fare concessions have been used in Cape Town to shift some users from the congested peaks); and (3) incentivise a modal shift from private to public transport (to reduce external costs of car use, such as GHG emissions).

Pillay and Ngcobo (2015) focus, in particular, on ways of implementing a more effective pro-poor fare policy on Johannesburg's Rea Vaya Bus Rapid Transit system. Their analysis considers three groups of fare structures: distance-based options; flat fare options; and hybrid options. The hybrid options involve specific targeting of fare discounts to poor areas, one option applying a fixed lower flat fare for all travel from poor areas and the other applying fare discounts that increase as the level of poverty in an area increases. These two hybrid options produced the best results, in terms of household savings accruing most effectively to the intended poor households, with the lower flat fare option having the benefit of simplicity to implement. The authors argue that, in a context of tight government funds, the increased subsidy payments required for such a pro-poor fare policy should be met by levying a transport tax on higher income households or a property tax, a matter to which we return in section 5. They note, too, that applying any such pro-poor fare discounts to the formal public transport sector leaves untouched the minibus (taxi) sector, which plays a larger transport role for the poor in South Africa. As a consequence, fare policy needs to be framed more broadly.

Two Workshop papers discussed fare evasion as a public transport policy issue. If fare evasion can be cost-effectively reduced, whatever the ruling fare policy, then the sustainable funding challenge is made somewhat easier. Guarda et al. (2015) identified a number of factors that help to explain the level of fare evasion on Santiago public transport. The explanatory variables that were found to be statistically significant included the level of inspection, the proximity to a metro or intermodal station, the level of bus occupancy, period of the day, geographical location and the number of passengers boarding and alighting at a bus stop. The authors develop an optimizing (revenue-cost) model to help improve the effectiveness of ticket inspection strategies, showing that these strategies can be net revenue positive without necessarily having to fine fare evaders. They find, for example, that effectiveness can be improved by better targeting of inspection regimes to take account of area income and time of day, fare evasion varying with these two factors.

Bucknell, Muñoz, Schmidt, and Navarro (2015) examine the 'emergency trip' feature of the credit-based fare system that exists in Transantiago. This system gives credit to users with insufficient funds on their smartcards, from 9pm to 9am. The paper evaluates a methodology to infer involuntary fare evasion (those who want to pay but have insufficient funds on their card), through analysis of smartcard system data. This methodology is applied in a pilot evaluation to assess the impact of extending the benefit availability period from 9am to $11 \mathrm{am}$ (with no change to the start time of 9pm). The analysis showed that an unannounced extension could effectively reduce fare evasion but that evasion increased if the extension was announced. The authors suggest some ways in which the latter effect might be mitigated, such as requiring higher minimum card balances.

Analyses of the type reported in these two fare evasion case studies are useful ways to increase net revenue flows to public transport operation, contributing to a more sustainable funding outlook.

\section{Public transport benefits}

Identifying and valuing the various benefits and costs associated with public transport service provision was the most substantial discussion topic of Workshop 3. Participants identified the following benefits:

- user benefits

- non-user benefit (option value/existence value)

- agency benefits (including changes in costs of competing modes)

- positive externalities from public transport (such as 'wider economic benefits')

- reduction in negative externalities (particularly from use of competing modes)

- safety and security

- brand value

- fostering stronger communities, building social capital and supporting livability.

Some other 'benefits' were also considered but these can largely be subsumed in the above generic list. In discussion it was noted that some of the listed benefits might be capitalized into land values, an area of increasing focus for funding service improvements (discussed in section 5).

User benefits from public transport are associated with the value of the opportunities that can be accessed by public transport, compared to the generalized travel costs (especially time, money and accident risk) of accessing those opportunities by available alternatives. How travel time is used affects this value: thus, if public transport allows passengers to use time-in-motion effectively, this contributes to the value of the service. Non-residents (visitors) who can travel about because of the presence of public transport also receive user benefits.

Net user benefits of a public transport service are often measured as the consumers' surplus accruing to users of the service, which represents the difference between total willingness-topay and the amounts actually paid by users. ${ }^{1}$ If a change in service level is being evaluated, then the relevant user benefit measure is

\footnotetext{
Or by a similar measure such as compensating variation.
} 
the expected change in consumers' surplus. Mohring (1972) showed how there can be increasing returns to scale in user benefits through virtuous network effects.

One type of non-user benefit accrues not because of a specific use of public transport, but because of the option of such use, should a person so wish. Transport provides access to potential destinations, some of which may result in trips, but the existence of the possibility of a future trip via transit may also have value today. Also, some people may place a value on the existence of public transport services for use by others, even though they may never intend to use those services personally. Such existence value is an altruistic value, applied more usually in the environmental field but also of some relevance to public transport. While there is research on some relevant option values, workshop participants were not aware of any specific valuation work on existence value as it applies to public transport.

Agency benefits are the benefits that accrue to some other public entities because of the activities of public transport. For example, road maintenance costs will be reduced if rail improvements lead to a modal switch from road to rail.

A key concept for transport policy is that of an externality, which Pearce and Nash (1981) define as unpriced goods or bads that accrue to third parties. Production externalities arise when the production possibilities of a firm are influenced by the unpriced activities of another firm or by a consumer. The agglomeration (productivity) benefits that accrue to businesses in large cities, which are likely to depend in part at least on urban heavy rail, metro or Bus Rapid Transit capacity, are a relevant example of positive externalities from public transport. These benefits that arise from urban clustering are made possible because of the capacity of public transport to move large numbers of people in to/out of activity centres. Other wider economic benefits, such as economic benefits arising from improved labour supply, may also be applicable to public transport, as estimated (for example) in UK Crossrail appraisals. Benefits of this kind, which flow from accessibility improvements, are likely to be reflected in land prices. They are sometimes estimated using computable general equilibrium models, which enable flow-on impacts to Gross Domestic and/or Regional Product to be estimated. Such modeling can include an estimate of the benefit that accrues to government(s), through their taxation powers, such as income tax, company tax and sales tax these enable government(s) to appropriate part of the resulting benefit, an argument for governmental funding support that returns some of the benefit involved to support service improvement.

A number of studies have examined links between public transport service provision and land/property values. Mohammad, Graham, Melo, and Anderson (2013) present a meta-analysis of studies looking at the impact of rail projects on land and property values. Their research shows that the result depends on a range of factors, such as type of land use, type of rail service, rail system life cycle maturity, distance to stations, geographical location, accessibility to roads, data specification, methodological characteristics, together with whether the affected entity is land or property. While the mean value impact they identified was an 8 per cent gain, these influencing factors mean that there is a large variation in the range of impact values.

Dube, Rosiers, Theriault, and Dib (2011) summarize a few relevant analyses of bus rapid transit impacts on land/property values and present their own research on a BRT service in Quebec City. They found increases in property values following major bus improvements ranged from 2.9 to 6.9 per cent. Mulley (2014) has looked at the impact of Sydney's Liverpool to Parramatta Transitway (LPT) on property values. Her results are slightly smaller than those found for Quebec by Dube et al., Mulley suggesting that the different locations of the respective facilities within their respective cities may have contributed to this result (the LPT being in suburban Sydney but Quebec's facility serving the central metropolis).

These various empirical studies show the potential for value capture to help fund public transport projects, but also suggest show the difficulty of striking a charging rate and on deciding on the applicable charge area.

A major external benefit of most public transport services is the reduction in the external costs of road use that results from PT taking travellers out of cars. These external benefits include congestion cost savings, improved air quality, lower greenhouse gas emissions, lower accident costs and improved health (e.g., associated with increased physical activity involved in using PT, rather than travelling by car) and safety. There is an extensive history of valuing such benefits.

With increasing concerns in many cities about safety and security, public transport can provide community benefits through what Jane Jacobs (1961) referred to as 'eyes on the street'. The presence of people tends to increase safety and to increase the perception of safety, although workshop participants were not aware of any specific valuation work on this benefit.

Cities may also gain a benefit from the brand value associated with their public transport network, or parts thereof. For example, Melbourne is widely recognized internationally for its tram system, Curitiba and Bogota for their BRT systems, and London, Paris and New York for their underground rail systems (known respectively as the tube, metro and subway!). This branding presumably has some international marketing value, attributable to the public transport service, although valuation remains elusive.

A potential external cost associated with public transport, given the connection between accessibility and land prices, is the gentrification that is often associated with transit-oriented development (TOD). More compact settlement patterns commonly focus on increasing the extent of TOD but gentrification is a common unintended consequence, pricing out existing residents. Clearly additions to the housing market overall at a rate faster than population growth should reduce average prices, all else equal. Nevertheless locally prices may increase. There are a variety of strategies to address those who are priced out of the market. The most straightforward such strategy is cash payments to existing renters. Planning agencies seldom have cash, and try to achieve their ends through regulatory means. For example, measures such as inclusionary zoning, which requires a proportion of affordable housing in a new development, linked to density bonuses if that housing is supplied, are often used for this purpose. In general, integrated land use transport planning seeks to increase affordability of housing while delivering more compact settlement patterns.

Workshop discussion also mentioned the possibility of public transport creating benefits through means such as helping foster stronger communities, build social capital, support livability (a somewhat elusive concept) and support greater equality, through providing a social safety net and easing household budget pressures (e.g., through reducing the need for household car ownership and storage. Quantification and valuation work in such areas is only at an early stage. For example Stanley, Stanley, and Hensher (2012) have measured sense of community and social capital and derived values for a unit change in these measures but are not able to say what public transport improvements might cause such a unit change. Recent macro-economic research is showing how more equal societies also have higher GDP but links to public transport as a means of promoting greater equality have not been linked to such findings. These remain areas for potentially fruitful research.

Two Workshop papers that focused on particular aspects of benefit measurement were Ermagun and Levinson (2015) and 
Larrain and Muñoz (2015). Ermagun and Levinson examine the relationship between employment accessibility (defined in terms of the number of jobs that can be accessed within $30 \mathrm{~min}$ by public transport, net of jobs that are accessible by walking only) and various aspects of public transport service provision in 46 of the largest 50 US metropolitan areas. They find that a $1 \%$ increase in PT operating expenses is associated with a $0.71 \%$ increase in the number of jobs that can be reached by PT within $30 \mathrm{~min}$. Similarly, and encouragingly, they find that a $1 \%$ increase in vehicle revenue kilometres is associated with a $1.01 \%$ increase in accessibility, as defined. Their research does not find any conclusive support for increasing or decreasing returns to scale in terms of employment accessibility by public transport. By implication, US policy makers interested in pursuing jobs growth should expect to support this with a proportionate increase in public transport service, for an effective outcome. Agglomeration analyses can help to refine this expectation.

An interesting finding in the Ermagun and Levinson (2015, p.10) paper is that ' ... using the same operating expenses for bus and rail transit systems, the bus transit provides roughly 4 times net transit accessibility than rail transit'. This result is perhaps linked to the decentralization of jobs in US cities over recent decades and the greater flexibility of bus in catering for changing demand patterns.

Larrain and Muñoz (2015) point to the fast growth in express bus services, particularly Bus Rapid Transit services, since 2000, but note that there is no consensus about how best to design such express routes or about the conditions under which they will generate the most benefits. Their paper reported on an experiment in which a proposed design algorithm optimized almost 1000 scenarios. A model formulated for the purpose estimated the benefits of operating express bus services as a function of various corridor attributes. System performance is measured through user costs and system costs. In terms of the variables that effect outcomes on these measures, the authors take account of demand characteristics, system operating characteristics and relative weights of cost components (e.g., various unit time values). They find that the attractiveness, or value, of express bus services increases with increasing dwell time, an increasing number of stops per trip or average trip length, an increasing number of trips on the system, increasing travel time, an increasing concentration of trips on a limited number of O-D pairs, increasing critical arc load as a proportion of the load for all trips, decreasing vehicle capacity and decreasing values of wait time. Taking account of such factors in system design should help to increase the user benefits from service provision, net of system costs. External costs are not included as part of the analysis.

\section{Aspects of efficient service delivery}

Some Workshop papers considered aspects of the way public transport services are provided, looking at ways to improve efficiencies. Successful achievement of such efficiencies reduces the prospective public transport funding requirement, as with the fare evasion measures discussed above. Oliveira, Ribeiro, and Macário (2015a) considered how flexible auctions for provision of major, long lasting transport services can be most efficiently structured, with a view to application in the public transport sector. They note that procedures that have evolved in the road sector need adaptation for rail application, because of the common requirement for major capital expansions during project life in the latter case. They discuss the merits of the Least Present Value of Net Revenue approach, which has evolved in the roads sector, separation of capital expenditure and operational expenditure within this approach and the incorporation of expansion investments. The importance of the client (and bidders) recognizing the time distribution of revenues and outlays, how these can affect incentives in the bidding process and the ways in which triggers and other mechanisms can be used to optimize outcomes (minimize the present value of net outlays that are obligated) are shown to be important.

Chung and Hensher (2015) explore the way public sector management and oversight and private sector resources are combined in PPPs to create value in the provision of a good or service and how control mechanisms are used to balance concerns over transaction hazards. Through stated preference analysis of participants' experiences in road infrastructure PPPs, they find little support for the idea of shared value creation, through combining resources, as a stand-alone driver of PPPs but identify an important role for public control mechanisms, helping to mobilize private sector resources to improve transport network efficiency in the process of value creation. Public policies and mitigating controls support a shared value creation process. The private sector's capacity to manage traffic risk and finance is valued by the public partner, while the public sector's capacity to manage network risks is valuable to the private partner

The risky nature of PPPs and inevitably strong interdependence between the parties (partners) emphasizes an important role for trust. Private parties are more likely to enter a PPP if they trust the government, whereas the authors find that the public partner is more likely to view the private partner as untrustworthy and look for control mechanisms. Where trust is absent, the public partner will focus on ensuring well-defined and executed projects with contractual transparency, to safeguard quality and guard against opportunism. Overall, the authors conclude that (Chung \& Hensher, 2015, p. 32, p. 32)

PPPs, bringing together public sector's legitimacy advantages and private sector's advantages in managing market risks, create a repertoire of valuable resources that benefit private investors [and] at the same time produce public benefits for the society at large. The value creation path however is subject to challenges from social activism. The difficulty to contract for the effort to manage social activism highlights the role of trust.

A social activist might add that the best way to manage risks of social activism is to run open and accountable land use transport planning and project delivery processes, which deal with concerns in the right way at the right time.

Oliveira, Filho, and Macário (2015b) examined five Public Private Partnership contracts in Portugal (3) and Brazil (2), where the former, but not the latter, exhibited optimism bias. They recognize the potential value from PPPs and how this form of arrangement has helped to increase infrastructure investment in Portugal but also note the poor outcomes that have been achieved in many cases, including their three case study examples from Portugal, where patronage outcomes were all considerably less than forecast. Their paper focuses on the nature of risk transfer between government and the winning bidder under the respective sets of contracts, to shed light on whether this is likely to have contributed to the differing effectiveness of the PPPs. They conclude that the government preparedness to share downside risks in the Portugal examples encouraged excessively optimistic upside bidding in those contracts, compared to the Brazilian examples studied. While the authors acknowledge that other factors may also have influenced project outcomes, their findings underline the importance of good risk transfer mechanisms. In some cases, the risk problem is tackled by separating bidding for the design/build part of a project from the bidding for the operation stage, the completed project being put to market after traffic volumes have settled.

Merkert et al. (2015) looked at 58 BRT systems, from Latin America (18), Europe (12), Asia (12), North America (8), Oceania (6) 
and Africa (2), to assess factors likely to increase yield and system efficiency. They found no significant association between system yield and BRT system standards, although the yield measure used in the analysis (fare revenue per passenger) may need some refinement, because it will often be primarily a reflection of government fare setting policies, particularly since many of the systems analysed were publicly owned, rather than being associated with service quality and performance. In terms of the technical efficiency of the systems examined, the authors found that the most important determinant was the number of stations for the system. They also found that public ownership was beneficial for technical efficiency in two of three of their models, which challenges many prior Thredbo assumptions! They suggest that this association may reflect the relative advantage of the public sector for investing in BRT infrastructure. The paper also found that higher quality systems are not necessarily more technically efficient.

\section{Funding public transport}

The Hauge (2015) paper to the Workshop drew on an early 20th century Norwegian analysis of fishery management, a precursor of studies such as Hardin (1968) 'tragedy of the commons', to show how marginal cost road pricing of congested road conditions can deliver better societal outcomes than simply allowing users to battle it out. It does this by making users take account of the costs their travel decisions impose on others, as well as their private costs. This can be expected to lead to some private car users shifting to public transport services, others changing trip timing or destinations and others simply cancelling trips, the net effect also being likely to reduce the need for investment in additional road infrastructure. He pointed to potential adverse distributional consequences of such pricing reform but argued that the societal benefits are such that losers can be compensated for their loss, which could be by providing better public transport travel opportunities funded by the road charge. Hauge suggested that the requisite road prices, to correct private to social user cost, might be lower than anticipated.

Ljungberg (2015) reported the results of marginal social cost pricing analyses of cars and public transport in a Swedish case study. He found that the degree of internalisation of marginal social costs for petrol-fuelled cars in Sweden is 70 per cent in urban areas, 140 per cent in rural areas and slightly less than 100 per cent on average. Diesel-fuelled cars almost pay for their marginal social costs in rural areas but, due to higher environmental costs, pay much less than the relevant marginal social costs in urban areas, even compared to petrol-cars. Long distance passenger trains generally pay for the external costs they cause, except on infrastructure with capacity problems and in rural areas with a lower rail-track charge. He also found that bus pays for its total social cost to a lesser degree than passenger trains.

Importantly, Ljungberg found that fuel taxes set at a level to cover the marginal social (external) costs of road passenger vehicles would more than fully cover an optimal subsidy for local and regional public transport in the rural county in which the Swedish case study was undertaken. Also, fuel taxes set to internalise the external effects of road passenger transport seem to cover an optimal public transport subsidy in Stockholm County, but this conclusion was less obvious than in the rural county.

Overall, the financial consequence of social surplus maximisation of local and regional public transport, including peakload pricing, in Sweden would be a subsidy level somewhere between 40 and 60 percent for public transport, depending on different circumstances in each municipality. Ljungberg makes the important point, however, that implementation of such a pricing scheme in Sweden needs to tackle some legal aspects related to funding public transport. In particular, public transport is financed at county level, while the taxes and charges levied on road traffic are a national revenue stream. Appropriate revenue flows would need to be negotiated before implementation.

Wang (2015) reviewed experience with value capture and its implementation. She noted how pressures on government budgets has encouraged the search for new revenue raising opportunities and that there are efficiency and fairness arguments supporting value capture mechanisms, with public transport a good candidate for application. Land value capture policies have the virtuous characteristic that they create incentives for land use transport integration, to maximise revenue raising opportunities. However, successful implementation involves legal, political and administrative challenges. Wang argues that there are several requirements for successful implementation:

- a promising regional economic growth setting and favourable real estate market, providing a good economic setting for value capture;

- integrated land use transport planning, including TOD precincts, that will maximise opportunities for accessibility enhancement on which value capture depends (it is not guaranteed);

- policy alignment across levels of government with an interest in the urban planning/revenue raising and allocation issues involved;

- shared goals across governments and developers about maximizing land value capture potential; and

- sufficient governmental capacity in (1) administration of a land value capture scheme, (2) negotiation of land acquisition at a favourable price (if site consolidation requires government involvement) and (3) ability to handle complex PPPs.

Briones and Bull (2015) reviewed decision making relating to introduction of public transport subsidies in Chile in 2009, to see what conclusions could be drawn about motivation for this significant national policy change. They noted the dire financial situation in Chile in general, and in the net financial position of the newly introduced Transantiago public transport system in particular, at the time, pointing out how the resolution of the latter PT financial loss involved subsidization of public transport both in Santiago and more broadly in Chile. Their analysis explores public interest rationales for subsidies (e.g., the need to subsidize student fares to support educational participation, without increasing fares for adults, which would be a disincentive to use services and increase external costs; equity between regions) and private interest factors (e.g., the need to garner political support). Their analysis suggests that both sets of factors were in play in Chile but that private interest factors were more important to the ultimate decisions that were taken. They conclude that the best policy instruments that we can aspire to implement are likely to be suboptimal, reflecting Bismarck's thinking about politics being the art of the possible.

Stanley (2015) provided an overview of potential funding measures for urban public transport and suggested criteria for choosing between these measures. He summarized the various funding measures into four categories:

1. Broad measures that are good at raising revenue, with positive beneficiary pays characteristics, that should be technically easy to implement, do not raise major equity concerns and are relatively transparent (e.g., property taxes; employer levies; metropolitan improvement levy). These measures have a lot going for them as ways of funding improved public transport;

2. Measures that mainly target road users (polluter pays/user pays) and, over time, have the potential to raise substantial sums (e.g., 
HOT lanes; fuel taxes; carbon taxes; road tolls; road pricing reform). Equity concerns will be significant, indicating the need for programs to deal with these concerns. Implementation costs for some measures (e.g., road pricing reform) are likely to be high but the prospective long term benefits are substantial;

3. Measures that are targeted at value increases from major placebased initiatives (e.g., metros, light rail transit, BRT) and have the potential to raise significant revenue. Equity is unlikely to be a major issue, because of opportunities for targeting and the focus on capturing part of value increases, and implementation can usually draw on successful examples (e.g., special assessments, Tax Increment Financing and developer charges);

4. Measures that have some revenue raising potential but issues for reasons such as equity and/or undesirable impacts on travel choices (e.g., increasing PT fares). Raising additional revenue from this source is best aligned with road pricing reform and with improved public transport services, including niche services that can command higher fares. Equity issues require attention.

Workshop participants drew on the discussion of public transport benefits and on the research in various workshop papers discussed above to consider how various possible funding mechanisms might be bundled together to fund public transport services and service improvements. Two scenarios were developed: the first where pricing measures are in place to ensure that travellers meet the various external costs associated with their travel choices, through marginal social cost pricing; the second assumes a lack of such pricing, particularly for car use. If road use is priced as in Scenario 1, the argument for subsidising public transport because road users are not meeting their social costs disappears. Prima facie, then, public transport users should also be expected to meet the marginal social costs attributable to their travel choices. Welfare maximizing pricing indicates setting prices at short run marginal social costs. If this does not produce sufficient revenue to meet governmental cost recovery targets, additional revenue should be raised charging higher prices to users least deterred by those higher prices - although developing such a fare-setting regime is a challenge! Alternatively, the gap could be covered by some level of government, in a way that minimizes welfare losses. If governments wish to subsidize the travel costs of particular categories of user, for reasons such as supporting social inclusion, then this should be explicitly identified and funded as such.

\subsection{Scenario 1: marginal social cost pricing for road use in place}

Fig. 1 illustrates how a marginal social cost pricing approach might appear in terms of covering operating costs, assuming that
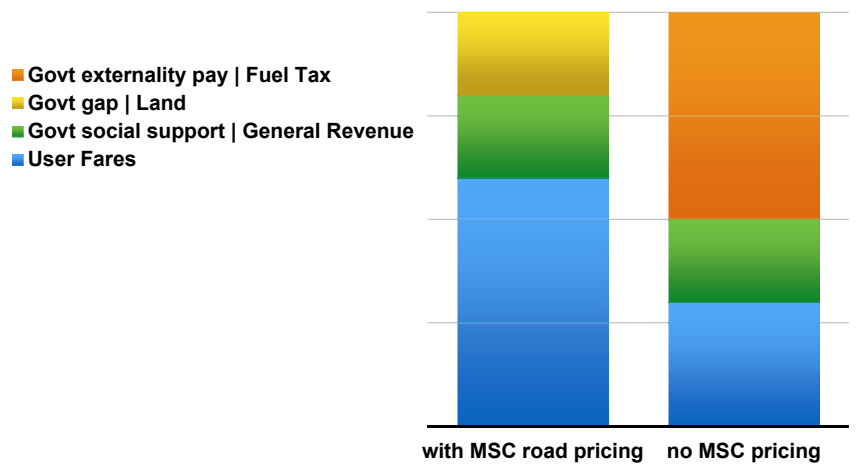

Fig. 1. Funding public transport operations. the cost of meeting government social objectives for the service accounts for about 20 per cent of operating costs and also assuming that there is no funding gap (i.e., break-even is pursued on operating costs). In calculating the break-even fare requirement, the figure includes provision for an externality offset in scenario 1 (MSC road pricing in place). This offset recognizes that public transport is likely to support agglomeration benefits, which will be sustained whether or not marginal social cost pricing of road use is in place (the quantum for this external benefit shown in Fig. 1, at about 20 per cent of operating costs, is an assumption not based on any particular data base. It is simply intended as a reminder to recognize this external benefit in fare setting). These agglomeration benefits cannot be captured by public transport operators, accruing to the wider community as an external benefit, with the national level government typically capturing a significant part of this benefit via its comprehensive taxation powers. Some Government funding support to public transport, in recognition of this external benefit and governmental revenue gain, is assumed and shown as an externality offset. This external benefit is likely to be large in the case of trunk public transport to a city's central business district.

\subsection{Scenario 2: no marginal social cost pricing of road use}

Marginal social cost pricing of road use is uncommon. In the absence of such pricing, how might public transport services be funded? Application of the beneficiary pays principle says to look for possible net external benefits that might be attributable to the existence of public transport services and recognize these in fare setting. These net external benefits might be reductions in the external costs of car use, because of the existence of public transport services, and might also include positive agglomeration benefits attributable to public transport services (particularly CBD oriented rail services), as identified in scenario 1. Fig. 1 assumes that the relevant external benefits sum to about 50 per cent of operating costs, with 20 per cent for agglomeration benefits as in Scenario 1 plus an additional assumed 30 per cent for reduced external costs on other modes). That leaves about 30 per cent of operating costs to be covered by fares.

This general approach has been taken in Sydney (for example), by the Independent Pricing and Regulatory Tribunal (IPART) in its public transport fare setting deliberations for that city. For urban route bus services, IPART calculates the level of costs that should be met from fares as follows (IPART, 2013, from Table 1.1 in that report), assuming efficient service costs as a starting point:

- Calculate the total efficient costs of the benchmark operator

- Less the efficient cost of providing school services (deducted to derive the costs of route bus services)

- Less non-fare revenue

- Equals net efficient costs of the benchmark operator

- Less the value of external benefits for the benchmark operator

- Equals Revenue requirement

- Less government subsidy for concession fares

- Total amount that should be funded by passengers (from fares)

This IPART calculation suggested that fares should pay for about 40 per cent of the efficient service costs for route bus services in Sydney, with government meeting about 60 per cent because of the external benefits from bus services and government desire to support concession fares. The costs used by IPART are arguably higher than marginal social costs because they include depreciation and return on capital, which are part of the contractual payments to bus operators (about 19 per cent of efficient costs as they are calculated) but arguably should not be included within short run marginal costs for efficient fare setting. Also, IPART does not 
account for agglomeration benefits or social inclusion benefits beyond those implied in fare concessions. However, the general approach adopted by IPART is useful for illustrating how net external benefits and government-assessed social benefits can be taken into account via a government payment in the fare setting process, to net out the proportion of costs that should be sought from users, government payments representing beneficiary pays contributions towards cost recovery and payments for distributional reasons.

Fig. 1 illustrates how scenario 2 might distribute operating costs between various funding sources, with government being the means of funding the net external benefits and social benefits. The 'social benefit' component should be the same proportion between both of the two scenarios. The essential difference between the two scenarios is that government pays for all the net external benefits of public transport in scenario 2, where there is no pricing of the external costs of road use, but only for the agglomeration externalities in scenario 1 .

\subsection{Funding the government contribution}

How might government raise the revenue to meet its net external benefit contributions required in Scenario 2? A number of possible measures were discussed by Workshop participants, with Stanley's category 1 measures being seen as most appropriate. These were described as "broad measures that are good at raising revenue, with some positive beneficiary pays characteristics, that should be technically easy to implement, do not raise major equity concerns and are relatively transparent (e.g., property taxes; employer levies; metropolitan improvement levy)'. Participants concluded that tax efficiency arguments favour land/property based measures over employer levies. Well-designed land/property taxes do little to change incentives to work, save and invest. Participants therefore concluded that land, or property, should be the basis on which government raises the funding to pay for net external benefits from public transport, with a low rate broadbased charge being most appropriate for on-going service support. The linkage between public transport services and land values is supportive of this approach.

Where funding of public transport service improvements (capital) is being considered, land (and to a lesser extent property) again should figure prominently as a means of beneficiary pays funding, through developer charges and other value capture mechanisms, based on project specific value capture estimates for projects like CBD rail, light rail and Bus Rapid Transit, which can have substantial revenue raising potential. Placing the onus on land, rather than property, provides an incentive for more intensive land development, which is consistent with the idea of the compact city. User fees plus beneficiary pays for net external benefits, based on land/ property, provides a solid base for funding urban public transport, supported by specific government funding for social inclusion benefits.

Over time, reformed road user charging, as in Scenario 1 (based on mass, distance and location and reflecting all the external costs of road use) should be pursued, which would support better resource allocation efficiency across the whole land transport sector.

The particular revenue streams that might be best suited to support public transport service provision and upgrading may accrue to the level of government with responsibility for public transport service provision. This is a convenient outcome but will not always be the case. For example, fuel excise/gas tax revenues, land/property revenues and parking charge revenues are all candidate revenue streams but may accrue to different levels of government. Any opportunity for the level of government with responsibility for public transport service delivery to draw on such multi-governmental revenue streams will usually require formal funding agreements between the respective governments, which are common practice.

\section{Recommendations for research, policy and Thredbo 15}

\subsection{Research and policy}

Extend research/policy analysis on the following matters:

- Use of land valuation, and changes therein, as a central basis for public transport benefit measurement and as key funding source.

- Extending the process of monetizing the benefits of public transport, to expand funding opportunities.

- Assess the potential impact of future technologies on PT benefits and funding requirements/frameworks (e.g., mobility-as-aservice; electric vehicles, autonomous vehicles).

- Undertake benefit valuation research in developing countries.

- Better linkages between pricing, funding and service provision.

- Public choice theory rationales for sourcing and allocation of funds to public transport, including such issues as

- aligning fares policy and concessions with subsidy policy

- delivery of subsidies for social inclusion (to the individual or the operator?)

- defining who deserves a subsidy and at what level

- benefits and costs of hypothecation

- intergovernmental co-ordination of public transport funding (what each level should do and why)

\subsection{Thredbo 15}

- Report on comparative studies of pricing and funding of public transport systems in cities of different scales, geographies and levels of development.

- Benchmarking of bus and rail benefits.

- Pricing/funding of public transport compared to other utilities.

- Linking accessibility and land value capture, in greenfield and brownfield settings.

- Monetization of the benefits and costs of public transport.

- How far can public transport operate from private sector funding (e.g., as with the London Northern Line extension)?

- Funding implications of gross cost and net cost contracts.

- Fiscal federalism and public transport.

- The national government as a beneficiary of good public transport and the funding implications thereof.

- Social support: funding individuals or systems

\section{References}

\section{Workshop papers}

Briones, J., \& Bull, O. (2015). The politics of public transport funding: A case study of the legislative process of the 2009 subsidy act in Chile.

Bucknell, C., Muñoz, J. C., Schmidt, A., \& Navarro, M. (2015). The impact on fare evasion of a credit-based fare system in Transantiago.

Chung, D., \& Hensher, D. (2015). D public private partnerships: Shared value creation, trust and control.

Ermagun, A., \& Levinson, D. (2015). Accessibility and transit performance.

Guarda, P., Galilea, P. Handy, S. Muñoz J. C. \& Ortúzar, J. de D. (2015). Decreasing fare evasion without fines? A microeconomic analysis.

Hauge, O. (2015). An early analytical contribution for the regulation of road congestion.

Larrain, H., \& Muñoz, J. C. (2015). When to provide express services for buses?

Ljungberg, A. (2015). Marginal cost-pricing in the Swedish transport sector - An efficient and sustainable way of funding local and regional public transport in the 
future?

Merkert, R., Mulley, C., \& Hakim, M. (2015). Determinants of bus rapid transit (BRT) system yields and efficiency - A global benchmarking exercise.

Oliveira, M., Filho, R., \& Macário, R. (2015b). Using least present value of revenue auctions for public transport infrastructure: The value of the flexible CAPEX.

Oliveira, M., Ribeiro, J., \& Macário, R. (2015a). Are we planning investments to fail? Consequences of traffic forecast effects on PPP contracts: Portuguese and Brazilian cases.

Pillay, P., \& Ngcobo, J. (2015). Designing a more pro-poor bus fare policy for the city of Jonannesburg, South Africa.

Stanley, J. (2015). Public transport: Funding growth in urban route services.

Wang, S. (2015). Political preparation for implementing land value capture in Australia.

\section{General references}

Dube, J., Rosiers, F. D., Theriault, M., \& Dib, P. (2011). Economic impact of a supply change in mass transit in urban areas: A canadian example. Transportation Research Part A, 45(1), 46-62.

Hardin, G. (1968). The tragedy of the commons. Science, New Series, 162(3859), $1243-1248$.
Independent Pricing and Regulatory Tribunal. (2013). Maximum fares for metropolitan and outer metropolitan buses from January 2014. Transport Final report, IPART, November.

Jacobs, J. (1961). The Death and Life of Great American Cities. New York: Random House.

Mohammad, S., Graham, D., Melo, P., \& Anderson, R. (2013). A meta-analysis of the impact of rail projects on land and property values. Transportation Research A, 50, 158-170. April.

Mohring, H. (1972). Optimization and scale economies in urban bus transportation. American Economic Review, 591-604.

Mulley, C. (2014). Accessibility and residential land value uplift: Identifying spatial variations in the accessibility impacts of a bus transitway. Urban Studies, 51(8), 1707-1724.

Pearce, D., \& Nash, C. (1981). The social appraisal of projects: A text in cost-benefit analysis. London: Macmillan.

Stanley, J., \& Lucas, K. (2014). Workshop 6: Delivering sustainable public transport. Research in Transportation Economics, 48, 315-322.

Stanley, J., Stanley, J., \& Hensher, D. (2012). Mobility, social capital and sense of community: What value? Urban Studies, 49(16), 3595-3610.

Please cite this article in press as: Stanley, J., \& Levinson, D., Workshop 3 report: Sustainable funding sources and related cost benefit measurements, Research in Transportation Economics (2016), http://dx.doi.org/10.1016/j.retrec.2016.10.004 